\section{O QUE FAZ O BRASIL, BRASIL?}

\section{ROBERTO DaMATTA}

Rio de Janeiro, Rocco, 1989, 125 páginas.

\section{Por Fernando C. Prestes Motta}

Professor titular do Departamento de Administraçäo Geral e Recursos Humanos da EAESP/FGV.

\section{Garoto esperto!}

Quatrocentos e noventa

anos de conciliação.

Jamais ouvi de um japonês, de um canadense ou de um norte-americano nem mesmo a mais leve indicação de se considerarem patrícios de Deus. Entretanto, quantas vezes ouvi brasileiros expressarem de forma inequivoca essa idéia! Num livro intitulado Exploraçôs: Ensaios de Sociologia Interpretation, Roberto DaMatta, antropólogo brasileiro que täo bem tem captado as peculiaridades de nossa sociedade, analisa essa noção, lembrando que Deus é concebido como ideal de totalidade, totalidade que só se pode pensar a partir das divisóes infinitas nas quais o universo se apresenta, totalidade que, no caso brasileiro, só pode ser pensada como integração de dimensões bastante separadas, como a rua, a casa e o "outro mundo", integração que concilie o alto e o baixo, - forte e o fraco, o Estado, a sociedade e o cidadảo, a lei e a vida, o amigo e a autoridade, o "caxias" e o malandro.

Em casa, junto aos familiares, padrinhos e amigos, vivo no conforto das relaçóes pessoais, num mundo em que devo e recebo favores, no qual devo e me devem respeito, afeto e distinçăo. Na rua, ninguém me deve nada, eu e os demais cooperamos e competimos por recursos escassos sob o primado das regras, das leis e das normas das instituiçôes da vida econômica e profissional.

O que näo acho em casa, procuro na rua. E se não acho nem em casa, nem na rua? Sendo brasileiro, é provável que procure no "outro mundo", rezando, fazendo promessas, indo as igrejas, terreiros ou casas abertas aos aflitos em geral. Ê bem possível que eu vá a todos eles, que chame Nossa Senhora da Conceição de Iemanjẩ ou Iemanjấ de Nossa Senhora da Conceição.

A especificidade da cultura brasileira não está na separação entre as diversas esperas da vida, mas sim em sua integração. Com frequêencia, o Pai, no mistério da Santíssima Trindade, associado à lei $e$ a impesscalidade, o Filho, humanidade e ao pessoal e, ensina a Igreja Catolica, o Espirito Santo é o amor que os une. Essa idéla de Deus é fascinante, ao exibir totalidade diferença, fazendo do amor o cimento que relaciona Pai e Filho. A sociedade brasileira também se pensa dessa forma: divisão e relação. Para compreender a cultura de nossa sociedade, é preciso compreender que "o relacionar" é fundamental.

De modo mais sistemático, numa linguagem a cujo sortilégio é difícil resistir e igualmente diffcil não compreender, mesmo desconhecendo antropologia, Roberto DaMatta explora esse e outros temas em O que faz o Brasil, Brasil? Diffil também é não concordar com a tese ca impostbilidade de compreender o Brasil a partir de uma única causa ou principio social. $O$ que torna o 
Brasil compreensível é uma lógica comum que perpassa a sociedade, lógica que DaMatta chama relacional, a manifestar-se como negociação e conciliação, no dominio político, numa êntase na área pública que só tem paralelo no vigor da iniciativa privada, fazendo da economia brasileira um caso especial em muitos sentidos e num sincretismo religioso onde as crenças, rituais e práticas em geral das religiōes populares e, sobretudo, as de origem africana, convivem com o catolicismo romano, tendo santos católicos correspondentes entre os orixás.

Interessantes, igualmente, são as produçöes literárias, musicais e artísticas de todo tipo que essa sociedade exibe. Num país onde os espaços internos estão extremamente divididos, onde o luxo e a vida convivem com a fome e morte, onde o mais moderno capitalismo de oligopólios coexiste com a economia de subsistencia, onde as mais antigas superstiçoes e a tecnologia de ponta disputam espaços e mentes nas periferias das cidades ou nos classificados dos jornais, a música de Chico Buarque expressa as divisões, ao mesmo tempo que opera a mediaçäo. No fundo, gostando das músicas de Chico Buarque, irmanamo-nos de tal sorte que num tempo remoto na nossa consciência havia até quem dissesse que gostava do là do romântico do grande compositor-cantor.

Tendo a crer que o que de fato gostamos na música de Chico é o que ela traz de mais brasileiro ao expor divisões e integração. De fato, nós, brasileiros, tanto aspiramos ao total, à completude, que há até quem veja na nossa decantada hospitalidade, que talvez realmente não conheça outra similar, metafórica antropofagia a revelar-se na esfera cultural e afetiva. Não menos metaforicamente antropofágico parece o nosso racismo peculiar, o desejo de diluir no sangue brasileiro todas as raças e etnias, sempre no sentido de uma arianizaçăo beneficiada pelo melhor de cada povo ou raça. Disso não têm escapado mesmo mulatos e negros brasileiros ao verem, no sangue dos bantos e sudaneses, "o carvão para a fornalha das raças" ${ }_{*}$ o elemento propulsor do aperfeiçoamento racial, como colocou Cassiano Ricardo.

Parece ser usual ao brasileiro a opção pelos dois, quando dois caminhos se apresentam. Assim, o brasileiro exige, a um só tempo, que se the dispense o tratamento de indivíduo e o de pessoa. O de individuo, dentro da melhor tradição democrática, que confere a todos os homens direitos que são fundamentais, e o de pessoa, na melhor tradição aristocrática, que confere aos homens direitos desiguais conforme seu nascimento ou relaçốes sociais. Se isso parece a qualquer um

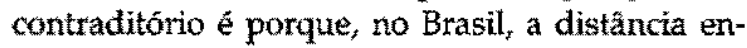
tre intenção e gesto que, segundo texto declamado pelo moçambicano e brasileiro Rui Guerra, herdamos no sangue lusitano, não difere da distância entre discurso e prática, salvo quando o empresảio progressista paga decentemente sua empregada doméstica e quando os juramentos feitos no altar são mantidos até que a morte os separe, quando o discurso revolucionário e o voto no "partido de esquerda" säo acompanhados da disposição do burguês médio, grande ou pequeno, de renunciar ao colégio "aberto" dos fithos $s_{r}$ a telas ou gravuras dos artistas da moda, ao automóvel prestigioso e outros pequenos luxos que garantem a reprodução social, à série alternada "pelicano, ovo, pelicano, ovo,..." divulgada pelo sociólogo Pierre Bourdieu. Isso parece difícil, é certo. Alias, mesmo alguns poucos casos, que observei ou de que ouvi falar, nunca me pareceram convincentes.

Se, para alguns, é dificil entender por que era tão italiano $O$ Guarani de Carlos Gomes, é igualmente dificil compreender o sucesso da lenda do lobisomen, a força de Cauby Peixoto cantando a composição de Chico Buarque, o enigma do personagem Diadorim, de Guimarães Rosa, o fenômeno Caetano Veloso, a perspicácia do manifesto antropof́ágico de Oswald de Andrade, a excitante Gabriela, de Jorge Amado, e a natural e sabida boneca de pano de Monteiro Lobato. Entretanto, todos esses fenômenos săo, entre muitos, a melhor expressão de nossa cultura, que permite a coexistência de um lado oficial e legal e de outro oficioso e pessoal, do critério impessoal e do tratamento pessoal, e até mesmo, de um Estado federativo que, sob tantos aspectos, mais parece unitário. Aliás, é comum ouvir no país a expressão: "Para os amigos tudo, para os inimigos a lei $i^{\prime \prime}$.

A leitura que DaMatta faz da sociedade brasileira indica o "estigma" de uma sociedade dividida onde, às vezes, se torna difícil perceber que os membros dos diferentes estratos sociais são patrícios que falam uma mesma língua, não apenas porque, com freqüência, a comunicação direta é difícil, como porque até os tipos físicos são muito diferentes; isso, para năo falar do que Bourdieu chamou "eixo corporal", conjunto de sinais de origem social que se referem aos gestos, movimentos, forma de expressão e vestuário. No 
Brasil, evidentemente, há ainda a desnutriçäo, a falta de saude, de educação formal e de oportunidades educativas extra-escolares e a precariedade da saúde pública e a baixa renda a refletirem-se em diversos comportamentos e situaçōes. Acrescentem-se a isso as diferenças de ordem econômica, social e étnica que, conjugadas, tornam também rico e pobre tipos muito diversos.

Entretanto, apesar da enorme gravidade dessa situação, DaMatta também evidencia a capaci dade quase ilimitada de sintetizar, relacionar $e$ conciliar o que caracteriza o brasileiro. Dificil imaginar no Brasil uma homogeinização semelhante a que ocorreu em sociedades como a norte-americana e a soviética, ou o perfil que, aos nossos olhos, parecem ter, muitas culturas orientais, entre as quais a japonesa. Por outro lado, também o individualismo - que nâo contradiz a homogeneidade cultural norte-americana, que se torna motivo de preocupaçôes em outros países desenvolvidos, notadamente europeus - não parece encontrar terreno muito fértil no Brasil. Ao sintetizar, relacionar e relativizar, o povo brasileiro mantếm o deslumbramento da descoberta e da invençäo; e é nessa capacidade que se deve investir, como forma de sair da crise social que assola o país - que mais parece um suicidio das elites que talvez tenham esquecido alguns dos traços que definem o que é ser brasileiro.

$\mathrm{O}$ brasileiro é capaz especialmente de fazer o Carnaval, momento supremo da lógica relacional, onde o impossivel inexiste, onde tudo e todos se combinam, onde o jovem executivo paga modicamente para desfilar ná Marquês de Sapucaí, em meio as crianças, jovens e velhos dos morros que, subitamente, se transformam em autênticos marajás indianos, em Luiz XVI e Maria Antonieta, em samurais, em artistas, políticos e outras personalidades locais. Não se podem esperar dos brasileiros comportamentos de americanos e japoneses. Num sentido muito especial, o que é preciso é "carnavalizar" a rua, isto é, possibilitar o reflorescimento da inventividade brasileira na sua capacidade relacional de integração das diversas esferas da vida. É claro, a vitória numa Copa do Mundo facilitaria muito. Se não der, até concurso de "miss" pode ajudar. Uma pequena ajuda, algo que se possa comemorar com uma boa feijoada ou um bom vatapá, comidas de brasileiro, que, além de tudo mais, são liquidas e sólidas a um só tempo, para que nada se deixe de lado $e_{r}$ entre um estado e outro, escolham-se os dois.

\section{AUTOMAÇÃO E MOVIMENTO SINDICAL NO BRASIL}

\author{
RICARDO TOLEDO NEDER, LAÍS WENDEL \\ ABRAMO, NAIR HELOISA BICALHO DE \\ SOUSA, GONZALO FALABELLA, ÁLVARO \\ DIAZ \& ROQUE APARECIDO DA SILVA. \\ São Paulo, Editora Hucitec, CEDEC \\ OIT/PNUD/PEA, 1988, 270 páginas.
}

\section{Por Elizabeth Bortolaia Silva \\ Professora do Departamento de Política \\ Científica e Tecnológica, Instituto de \\ Geociências da UNICAMP.}

Este livro adiciona muito ao conhecimento das recentes inovações tecnológicas e organizacionals na indústria brasileira. O argurnento central é que os processos de inovação técrica e organizativa nas empresas reforçam ou coibem o desenvolvimento de estruturas de poder democráticas, dependendo das condiçoes prevalecentes na sociedade. Esse argumento é desenvolvido ao longo de sete artigos.

$\mathrm{Na}$ introdução, Gonzalo Falabella relata experiências variadas de implantação de novas tecnologias e das alternativas de controle sobre os seus efeitos. A diversidade de vivềncias nos casos apresentados demonstra que algo pode ser feito pelos "destituídos" ou "ameaçados", para controlar o progresso técnico. Por outro lado, os casos apresentados por Falabella indicam que a crise de acumulação, na qual se acelera a difusão da tecnologia microeletrônica,não se resolve pela nova tecnologia porque a crise se refere a dimensôes econômicas e políticas antigas que não necessariamente são mudadas.

No primeiro capitulo, Alvaro Diaz enfatiza o mesmo aspecto de que a nova tecnologia está associada ao processo social e político e lágica de acumulação capitalista. $O$ conceito de modernização tecnológica é ampliado para além da automação microeletrônica. A modernização incluiu novas concepçôes de organização de empresas, mudanças no desenho e qualidade dos produtos $e$ padrôes de relaçôes entre capital e trabalho. Diaz argumenta que o Brasil se destaca dentre os países latino-americanos pela rapidez e extensto do uso de tecnologia de ponta. Face aos países desenvolvidos, o nível de modernização tecnológica é mínimo. Todavia, assim como no caso 